\title{
An uncertain death
}

Previously published at www.cmaj.ca

I n clinics recently, I sat with an 85year-old man and his two daughters. Despite my best efforts and experience, I couldn't be certain about his diagnosis. He had bilateral posterior upper lobe masses and yet looked remarkably well for a man assumed to have metastatic cancer, despite no known primary, negative bronchoscopy and a quite uncharacteristic chest CT scan appearance. We had talked about the uncertainties and the pros and cons of going this route or that to make a 'definitive' diagnosis, which could all too easily miss the mark or turn up something incurable. So he declined the percutaneous biopsy and chose instead a gentler route of some prednisone in case there was some variant on bronchiolitis obliterans or other inflammatory component to his illness. Two weeks into this therapy, he felt better and the masses seemed a bit smaller. Through several clinic visits and ongoing diagnostic uncertainty I had given him my best and felt that he knew this.

We hear much about 'patient-centred care' and 'evidence bases' these days, and while care should be rooted in practices that are evidence-based, it can only flower if the patient's particulars are included in the evidence base guiding the plan. So this man remained an enigma, but one very much alive, smiling and getting to the mall, a pleasure foregone before the prednisone. His willingness to do without the diagnostic pursuit helped restore the critical balance between uneasiness with uncertainty and the goal of providing care respectful of the individual. He was totally comfortable with his life and with whatever lay ahead.

What lay ahead was a hospital admission as his dyspnea progressed. He remained alert and a joy to chat with to the last. Along the way, exploring the possibility of a move to the Veterans wing, this former chaser of German submarines confessed that, he hadn't won
"World War II single-handedly, but ..." $\mathrm{He}$ declined again a percutaneous biopsy, a decision that was right on a number of levels, not the least of which was respect for himself. A day after that decision, he slipped away gently into the night. He died in peace without knowing, or needing to know, that those lung

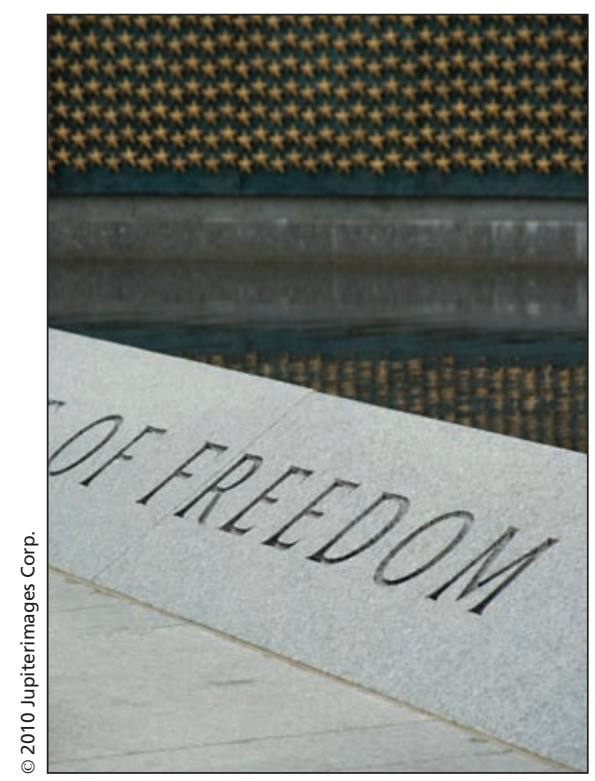

masses were indeed cancerous as proven by the subsequent autopsy.

In this era of patient-centred care and the CANMEDS six pillars of wisdom, we seem focused on the "fix" with its seductive illusion of certainty. There is precious little certainty in medicine, though we often delude ourselves to the contrary through an over-reliance on tests, the Internet, hand-held devices or the ever-evolving cottage industry of clinical practice guidelines and metaanalyses. Knowledge of the evidencebase is important, but it does little to explicate the story of the nature and effect of disease in a particular patient, his or her life and family at a particular time. Integrating the science of diagnosis and treatment into the art of clinical medicine must surely begin and end with concern for the care of the human being in front of us where we need to be so much more than highly trained, skilled technicians. In satisfaction surveys, patients and families tell us repeatedly that they want us to master the art of building a caring, attentive relationship so that trust and hope can flourish. ${ }^{1,2} \mathrm{We}$ need to be willing to sit down, listen to concerns, take time to explain our thinking and get the patient's take on possible options for moving forward, letting them know that we will do the best we can for them individually. ${ }^{3}$ We have to be willing to demonstrate, not just pay lip service to, the notion of care, and this includes having enough humility to say, I can't figure it out, enough concern to seek out someone who can, and enough integrity to not abandon the patient when no 'answers' can be found.

The obituary of our veteran was a wonderful tribute to a family man and chorister, a stalwart of, and much loved and cherished within, his wider community. During his last battle I had no diagnosis or cure to offer him, no fix, but I did what I could to maintain his hope, based on what I had discerned was important to him. Uncertainty being what it is, I did not know for sure whether this was enough. At the reception after the memorial service, I knew it was more than enough. I was kissed by his wife of 57 years and hugged by his daughters. "He thought the world of you," one of them said, "Because you worked out so quickly who he was."

\section{Graeme Rocker MD}

Professor of medicine

Dalhousie University

QEII Health Sciences Centre

Halifax, NS

Editor's Note: Signed consent to tell this story was obtained from the patient's widow.

\section{REFERENCES}

1. Heyland DK, Dodek P, Rocker G, et al. What matters most in end-of-life care: perceptions of seriously ill patients and their family members. CMAJ 2006;174:627-33

2. Heyland DK, Cook DJ, Rocker GM, et al. Defining priorities to improve end of life care in Canada. CMAJ 2010; Oct. 4 [Epub ahead of print].

3. Rocker G. You have to try. CMAJ 2010;182:1765-6. 